\title{
Use of a questionnaire to obtain an alcohol history from those attending an inner city accident and emergency department
}

\author{
T. G. BARRETT \& C. H. VAUGHAN WILLIAMS \\ Department of Accident and Emergency, The London Hospital, London, England
}

\section{SUMMARY}

A screening questionnaire designed to take an alcohol history was used on 996 patients $\stackrel{\widehat{\rho}}{د}$ attending the London Hospital Accident and Emergency Department. Questions $\vec{\varphi}$ concerned with 'binge' drinking detected many problem drinkers who were n\& identified by questions on weekly alcohol intake or 'CAGE' questions. The relatike increase in detection was particularly marked in women.

\section{INTRODUCTION}

Holt et al. (1980) suggested that up to $40 \%$ of patients in an accident and emergency department had previously consumed alcohol, determined by breath alcohol analysis.

Several surveys (Stockwell et al., 1979; Wallace et al., 1985; Redmond et al., 1987; Yates, 1987) have refuted the use of breath testing as a screening device for alcohol abuse. Patients may attend accident and emergency departments some time after an accident sustained while intoxicated and be sober at time of attendance.

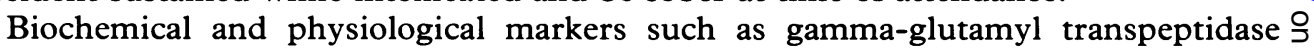
(GGT), mean corpuscular volume (MCV), urate and liver aminotransferase levels in $\frac{D}{O}$ the blood have also proved insensitive screening devices for alcohol abuse, (Stockwell et al., 1979; Chick et al., 1981; Bernadt et al., 1982; Kristenson et al., 1982; Wallace et al., $\sigma^{N}$ 1985; Royal College of General Practitioners, 1986). Clinical impressions have been N found to be extremely unreliable (Yates et al., 1987).

Many questionnaires have been written (Ewing et al., 1970; Selzer, 1971; Mayfield et

Correspondence: Dr T. Barrett, 46 Shelmerdine Close, London E3 4UX, England. 
al., 1974; Stockwell et al., 1979; Hilton, 1981; Wallace et al., 1985) but few have been used to screen patients entering an accident and emergency department (Redmond et al., 1987; Yates et al., 1987).

The Hilton Questionnaire, Hilton (1981), consisting of 32 items, identified 39\% of attenders at an accident and emergency department as being problem drinkers (Redmond et al. 1987), but is time-consuming to administer routinely in a busy department.

Researchers at the Centre for Health Economics, University of York, designed a short questionnaire to encourage doctors to take an adequate drinking history (Rowland et al. 1987). This questionnaire was used to obtain an alcohol history from attenders at an accident and emergency department (Fig. 1).

\section{PLEASE COMPLETE ALL QUESTIONS FOR ALL ATTENDERS AGED $16+$} DURING THIS PERIOD OF DUTY - and mark Casualty Card with 'AS' in top right hand corner so that attenders are not questioned twice.

\section{Age \\ Sex $M / F$}

How is your general health?

Do you drink alcohol at all? Yes/No

(IF YES), On average how many days a week do you have something alcoholic to drink?

DAYS

On average, on a day when you have something to drink, how much do you drink?

\section{UNITS}

ONE UNIT ALCOHOL HALF PINT BEER or LAGER, ONE GLASS WINE,

ONE MEASURE SPIRITS, ONE SMALL SHERRY/VERMOUTH etc TOTAL WEEKLY UNITS

Score positive for alcohol related

$$
\begin{array}{ll}
\text { problems if } 37 \text { units (men) } \\
25 \text { units (women) Pos/Neg }
\end{array}
$$

Most people have times when they drink more than usual, on occasion, do you drink:

(men) seven pints of beer or lager, or seven double shorts,

or 14 glasses of wine or sherry etc. or more?

Yes/No

(women) four and a half pints of beer or lager, or nine shorts, or nine glasses of wine or sherry etc. or more?

Yes/No

(IF YES) does this happen once a month or more?

Yes/No

Do you feel you should cut down your drinking?

Yes/No

Does anyone annoy you or get on your nerves by telling you to cut down your drinking?

Do you yourself feel bad or guilty about your drinking?

Yes/No

Do you drink first thing in the morning, to steady your nerves or get rid of a hangover?

Yes/No

DAY OR NIGHT

August 1987

Fig. 1 London Hospital Accident and Emergency Department: screening for alcohol-related problems. 


\section{METHODS}

The Accident and Emergency Department at the London Hospital sees approximately $\frac{3}{0}$ 80000 patients per year. There is a large Muslim population comprising more than $15 \%$ of attenders.

Two casualty officers used the York Questionnaire to interview 996 unselected patients, aged 16 years or more, attending the Accident and Emergency Department between September and November 1987. Patients were interviewed during representative sessions which covered every day and night of the week. During each session the casualty officers aimed to interview every patient they attended. Omissions were due either to the clinical situation or to the forgetfulness of the casualty officer. In such circumstances a questionnaire was marked to that effect and included in the final analysis.

Standard units of alcohol were used to assess consumption, one unit comprising one $\stackrel{\infty}{3}$. half pint of beer, lager or cider, a glass of wine, a small glass of sherry, or a single? measure of spirits.

Safe upper limits were those recommended by the Health Education Council (HEC) That's The Limit (1987): up to 36 units per week for men and up to 24 units per week for women. These were used to define those at risk.

The questionnaire consisted of three sets of questions.

The first set elicited the number of sessions per week and the average quantity drunk $\frac{3}{0}$ per session, thus giving the total weekly consumption of alcohol.

The second set identified binge drinkers. The definition of binge drinking for the purposes of this study was the consumption on one or more occasions a month of 1 te units or more by men and 9 units or more by women.

The third set of questions consisted of modified 'CAGE' questions (put in the present tense from the original past tense) (Ewing et al., 1970; Mayfield et al., 1974).

The questions were:

(1) do you feel you should cut down your drinking?

(2) does anyone annoy you or get on your nerves by telling you to cut down your drinking?

(3) do you yourself feel bad or guilty about your drinking? and

(4) do you drink first thing in the morning, to steady your nerves or get rid of a hangover? (eye-opener).

An individual was considered to be drinking excessively with two or more positive replies.

The answers were coded, and the data entered into a computer storage file and analysed using the Statistical Package for Social Sciences (London University).

\section{RESULTS}

The age and sex distribution of the study population is shown in Table 1 . There were 605 males and 379 females (sex of attender was omitted on 12 answer sheets). There were more men in each age group except the over $75 \mathrm{~s}$. 
Table 2 shows the percentage of those who admit to drinking alcohol, however infrequently, in each age/sex group. There is a higher percentage of male drinkers than female in each age group. Over all age-groups, after allowing for differences in age structure, the ratio of female drinkers to male drinkers was $76 \cdot 5 \%$.

Table 3 shows alcohol consumption per week for males and females for whom it was

Table 1 Total population by age groups and sex

\begin{tabular}{lcc}
\hline Age group & Males & Females \\
\hline $16-24$ & 182 & 118 \\
$25-34$ & 148 & 88 \\
$35-44$ & 81 & 46 \\
$45-54$ & 68 & 43 \\
$55-64$ & 65 & 23 \\
$65-74$ & 29 & 18 \\
$75+$ & 19 & 37 \\
Total & 592 & 373 \\
\hline
\end{tabular}

*Altogether there were 31 questionnaires in which either age and/or sex data were missing.

Table 2 Drinking population by age and sex

\begin{tabular}{lcccccc}
\hline Age group & Total & $\begin{array}{c}\text { Males } \\
\text { Drinkers }\end{array}$ & \% Drinkers & Total & $\begin{array}{c}\text { Females } \\
\text { Drinkers }\end{array}$ & \% Drinkers \\
\hline $16-24$ & 182 & 141 & $77 \cdot 5$ & 118 & 67 & $56 \cdot 8$ \\
$25-34$ & 148 & 107 & $72 \cdot 3$ & 88 & 62 & $70 \cdot 5$ \\
$35-44$ & 81 & 60 & $74 \cdot 1$ & 46 & 28 & $60 \cdot 9$ \\
$45-54$ & 68 & 44 & $64 \cdot 7$ & 43 & 18 & $41 \cdot 9$ \\
$55-64$ & 65 & 48 & $73 \cdot 8$ & 23 & 13 & $56 \cdot 5$ \\
$65-75$ & 29 & 14 & $48 \cdot 3$ & 37 & 7 & $22 \cdot 2$ \\
$75+$ & 19 & 9 & $47 \cdot 4$ & & $18 \cdot 9$ \\
\hline
\end{tabular}

Table 3 Alcohol consumption, men and women, all ages

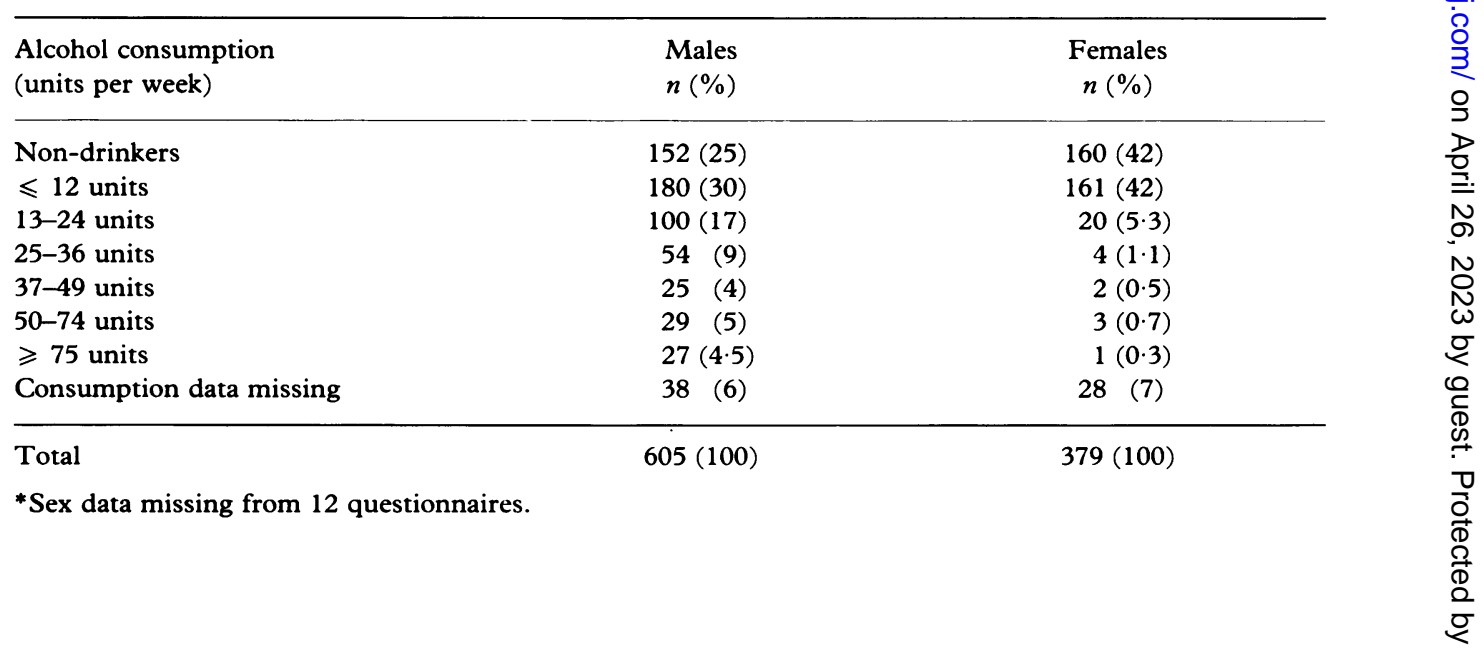


precisely known. Eighty-one (13.5\%) males drank more than the Health Education Council safe limits ( $>36$ units/week), compared to $10(2 \cdot 6 \%)$ females ( $>24$ units/ week), and $56(9.5 \%)$ males drank more than 50 units a week.

Table 4 shows the cases scoring positively for binge and 'CAGE', against alcohol consumption per week (not including abstainers).

For the binge questions, $151(25 \%)$ males and $29(8 \%)$ females scored positively. Of those, $82(13.5 \%)$ males and $24(6.3 \%)$ females were not identified by questions on alcohol consumption. Most of the attenders drinking more than 50 units a week also scored positively for binge (60 and 54 respectively).

With the 'CAGE' questions, $73(12 \%)$ males and $15(4 \%)$ females scored positively. Of these, $37(6 \%)$ males and five $(1.3 \%)$ females were identified who said they drank less per week than the recommended HEC limits.

One hundred and eighty-nine $(31 \cdot 2 \%)$ males and $40(10 \cdot 6 \%)$ females scored positively on one or more sections of the questionnaire.

Table 5 shows that 25-34-year-old males and females are most at risk of alcoholrelated problems (38.5\% males and $19.5 \%$ females in the age-group). The proportion of men scoring positively on at least one section is greater than $35 \%$ in all age-groups up to the age of 55 .

Table 4 Frequency of positive responses to binge or 'CAGE' questions, by alcohol consumption, men and women, all ages

\begin{tabular}{lrrrrrr}
\hline $\begin{array}{l}\text { Alcohol consumption } \\
\text { (units per week) }\end{array}$ & $M$ & $\mathrm{~F}$ & \multicolumn{2}{c}{$\begin{array}{l}\text { Cases scoring } \\
+ \text { ve for Binge }\end{array}$} & $\begin{array}{c}\text { Cases scoring } \\
+ \text { ve for 'CAGE' }\end{array}$ \\
\hline & & & M & F & M & F \\
$<25 \mathrm{u}$ & 280 & 181 & 56 & 24 & 27 & 10 \\
$25-36 \mathrm{u}$ & 54 & 4 & 26 & 1 & 9 & 1 \\
$37-49 \mathrm{u}$ & 25 & 2 & 19 & - & 9 & 1 \\
$\geqslant 50 \mathrm{u}$ & 56 & 4 & 50 & 4 & 28 & 3 \\
Totals & 415 & 191 & 151 & 29 & 73 & 15 \\
\hline
\end{tabular}

Table 5 Percentage of males/females in age group positive for alcohol abuse on one or more sections

\begin{tabular}{|c|c|c|c|c|c|c|}
\hline Age group & Total & $\begin{array}{l}\text { Males } \\
\text { Scoring }\end{array}$ & $\begin{array}{l}\text { Scoring } \\
\% \text { in group }\end{array}$ & Total & $\begin{array}{l}\text { Females } \\
\text { Scoring }\end{array}$ & $\begin{array}{l}\text { Scoring } \\
\% \text { in group }\end{array}$ \\
\hline $16-24$ & 182 & 65 & $35 \cdot 7$ & 118 & 11 & $9 \cdot 3$ \\
\hline $25-34$ & 148 & 57 & $38 \cdot 5$ & 88 & 17 & $19 \cdot 3$ \\
\hline $35-44$ & 81 & 29 & $35 \cdot 8$ & 46 & 6 & $13 \cdot 0$ \\
\hline $45-54$ & 68 & 24 & $35 \cdot 3$ & 43 & 1 & $2 \cdot 3$ \\
\hline $55-64$ & 65 & 11 & 16.9 & 23 & 3 & $13 \cdot 0$ \\
\hline $65-74$ & 29 & 2 & $6 \cdot 9$ & 18 & 1 & $5 \cdot 6$ \\
\hline $75+$ & 19 & 1 & $5 \cdot 3$ & 37 & 1 & $2 \cdot 7$ \\
\hline
\end{tabular}




\section{DISCUSSION}

The York Questionnaire, combining questions on weekly alcohol intake, binge drinking and 'CAGE' questions, takes less than 2 min to complete, and can be used as a rapid screening device when incorporated into the doctor's history.

A total of $13.3 \%$ of males and $3.3 \%$ of females admitted to drinking more than 36 and 24 units per week respectively. These figures are similar to those of Wilson in a national survey (14\% males drinking more than 35 units per week, and 3\% of females drinking more than 20 units per week) (Wilson, 1980a,b). This accident and emergency population had a higher percentage of male heavy drinkers $(9.5 \%)$, drinking 50 units a week or more, than the population in Wilson's survey $(6 \%)$. Those who drank most were the 16-54-year-old males and the 25-34-year-old females.

The figures on weekly alcohol consumption also follow a similar pattern to those of Yates et al. (1987) who found, in his accident and emergency population, that $7 \%$ of men drank more than 50 units per week and $2 \cdot 1 \%$ women drank more than 21 units per week.

There was a higher proportion of non-drinkers in the Whitechapel population $(27 \%$ of males and $46 \%$ of females) than found by Wilson or Yates, probably influenced by the large Muslim population.

The $13.3 \%$ of men and $3.3 \%$ of women who drank at least as much as the Health Education Council limits referred to are at risk from alcohol-related illness, Health Education Council (1987) That's The Limit.

It should be noted that more recently the (possibly) safe weekly limits have been reduced to 21 for men and 14 for women (Royal College of Physicians, 1987).

Two distinct aspects of alcohol-related problems are those relating to intoxication and to regular heavy consumption (Royal College of General Practitioners, 1986). There is considerable overlap, but problems relating to intoxication include social psychological and physical problems such as accidents and trauma, domestic violence, child abuse and suicide (Sabey et al., 1975; Murray, 1977; Royal College of General Practitioners, 1986). Thus any questions that relate to binge behaviour, giving some indication of frequency of intoxication, have relevance to accident and emergency departments. The York definition of 'binge' was chosen as the quantity of alcohol which would produce blood alcohol levels at least twice the legal limit for driving $(80 \mathrm{mg} /$ $100 \mathrm{ml}$ blood).

The binge questions had the highest detection rate of all the sections of the questionnaire. The relative increase in detection of at-risk attenders appeared to be particularly marked in women.

This survey has shown that two questions on binge drinking can identify many attenders at risk of alcohol-related problems not identified by questions on weekly alcohol consumption or by 'CAGE' questions.

\section{ACKNOWLEDGEMENTS}

We are grateful to Ms Nancy Rowland, of the Centre for Health Economics, University 
of York, for permission to use the questionnaire. We would like to thank Dr M. E. $\frac{\text { Th }}{3}$ Purkiss, Dr A. J. Silman, Mr A. W. Wilson, Miss Kathleen Davis and Miss Sheena $\frac{\mathbb{Q}}{\mathscr{Q}}$ Wright for their inspiration, advice and help with this survey.

\section{REFERENCES}

Bernadt M. W., Mumford J., Taylor C., Smith B. \& Murray R. M. (1982) A comparison of laboratory tests in the detection of excessive drinking and alcoholism. Lancet $\mathbf{i}, 325-8$.

Chick J., Kreitman N. \& Plant M. (1981) Mean cell volume and gamma-glutamyl transpeptidase as markers of drinking in working men. Lancet i, 1249-51.

Ewing J. A. \& Rouse B. A. (1970) Identifying the hidden alcoholic. Read at the 29th International Congress on Alcoholism and Drug Dependence. Sydney, Australia, 2-6 February.

Health Education Council (1987) That's The Limit.

Hilton M. R. (1981) The Hilton Questionnaire. In: Measure of Drinking Behaviour. Windsor, NFER Publishing.

Holt S., Steward I. C., Dixon J. M. J., Elton R. A., Taylor T.V. \& Little K. (1980) Alcohol and the emergency service patient. British Medical fournal 281, 638-40.

Kristenson H. \& Trell E. (1982) Indicators of alcohol consumption: comparison between a questionnaire (Mm-MAST), interviews and serum gamma-glutamyl transferase (GGT) in a health survey of middleaged males. British fournal of Addiction 77, 297-304.

Mayfield D., McLoud G. \& Hall P. (1974) The 'CAGE' Questionnaire: validation of a new alcoholism screening instrument. American fournal of Psychiatry 131, 1121-3.

Murray W. R. (1977) Head injuries and alcohol. In: Alcoholism: A New Knowledge and New Responser Edwards et al. (Eds). London, Croom Helm.

Redmond A. D., Richards S. \& Plunkett P. K. (1987) The significance of random breath alcohol sampling in the accident and emergency department. Alcohol and Alcoholism 22, 341-3.

Rowland N., Maynard A. et al. (1987) Doctors have no time for alcohol screening. British Medical fournal 295, 95-6.

Royal College of General Practitioners (1986) Alcohol-a balanced view. Report from general practice 24 November.

Royal College of Physicians (1987) A great and growing evil-the medical consequences of alcohol abuse.

Sabey B. \& Coding P. (1975) Alcohol and road accidents in Great Britain. In: Alcohol, Drugs and Road Safety. S. Isehstom \& S. Lamber (eds). Toronto, Addition Research Foundation.

Selzer M. L. (1971) The Michigan alcoholism screening test: the quest for a new diagnostic instrument. American Fournal of Psychiatry 127, 1653-8.

Stockwell T., Hodgson R., Edwards G., Taylor C. \& Rankin M. (1979) The development of a questionnaire to measure severity of alcohol dependence. British fournal of Addiction 74, 79-87.

Wallace P. \& Haines A. (1985) Use of a questionnaire in general practice to increase the recognition of patients with excessive alcohol consumption. British Medical fournal 290, 1949-52.

Wilson P. (1980a) Drinking in England and Wales. London, HMSO.

Wilson P. (1980b) Drinking habits in the United Kingdom. Population Trends 22, 14-18.

Yates D. W., Hadfield J. M. \& Peters K. (1987) The detection of problem drinkers in the accident and emergency department. British fournal of Addiction 82, 163-7. 